\title{
Evaluation of a Multi-Phase Trauma-Focused Intervention with Latino Youth
}

\author{
Anne S. J. Farina \\ Michael Mancini
}

\begin{abstract}
This pilot study examined the effectiveness of a multi-phase trauma-informed intervention with 24 trauma-exposed Latino youth. Treatment included a somatic-based intervention to target physiological hyperarousal symptoms and a sensory/cognitive-based trauma-focused intervention targeting stabilization of the trauma experience. Twenty-four participants completed several measures for mental health symptomatology and psychosocial functioning at baseline, at the conclusion of treatment, and at 3-month followup. Results of paired sample t-test analyses showed significant improvements in scores on measures for trauma, anxiety, depression, psychosocial functioning, and emotional dysregulation following 12 weeks of treatment when compared to baseline. Improvements were maintained at 3-month follow-up. This community-based intervention shows promise in helping Latino children who have experienced trauma. Research using randomized controlled designs with larger samples is suggested to further test the efficacy of this intervention.
\end{abstract}

Keywords: Post Traumatic Stress Disorder; trauma-informed treatment; Latino youth; mental health

Latino children in the U.S. experience various traumatic events such as exposure to political and other forms of violence prior to and during the journey to the U.S., maltreatment, sexual abuse, and parental deportation (Cuevas, Sabina, \& Milloshi, 2012; Dettlaff \& Johnson, 2011; Fortuna, Porche, \& Alegria, 2008; Rojas-Flores, Clements, Koo, \& London, 2016; Sedlack et al., 2010; U.S. Department of Health and Human Services 2015). Experiencing prolonged violence within a chaotic environment can lead to complex trauma that can impair the ability to regulate emotions, thoughts, and physiological reactions (Cook et al., 2005; Lawson \& Quinn, 2013). Physiological responses to traumatic events are associated with the body's natural stress response (i.e., fight or flee) and can lead to somatic reactions long after the trauma is over (Ogden \& Minton, 2000).

Trauma can lead to physiological reactions to both traumatic reminders and neutral stimuli that can activate states of hyper- or hypoarousal (van der Kolk, 1994). Hyperarousal may include sensations of feeling frozen, racing thoughts, aggression, fear and emotional reactivity or dysregulation, while hypoarousal may include collapse (i.e., fainting), dissociation and emotional numbness (Ogden \& Minton, 2000).

The high rate of violence experienced by Latino children and youth may make them more susceptible to difficulties with affect and behavioral regulation (Cook et al., 2005) that can lead to problem behaviors, depression, and anxiety (Buckner, Mezzacappa, \& Beardslee, 2009; Warner, Koomar, Lary, \& Cook, 2013). Furthermore, emerging evidence suggests that Latinos who have experienced trauma may experience more severe symptoms

Anne S. J. Farina, MSW, LCSW is a PhD student, School of Social Work, Saint Louis University, Saint Louis, MO 631031021. Michael Mancini, PhD is Associate Professor, School of Social Work, Saint Louis University, Saint Louis, MO 63103-1021.

Copyright $(2017$ Authors, Vol. 18 No. 1 (Spring 2017), 270-283, DOI: 10.18060/21296

(cc) BY

This work is licensed under a Creative Commons Attribution 4.0 International License. 
for longer periods of time and may be more likely to develop PTSD (Alcántera, Casement, \& Lewis-Fernández, 2013). They may also be more likely to report positive symptoms of trauma such as hypervigilence, emotional reactivity, hyperarousal, and intrusive thoughts than their non-Hispanic, white counterparts (Marshall, Schell, \& Miles, 2009).

Trauma intervention and research has focused on cognitive behavioral therapies (such as Trauma-Focused Cognitive Behavioral Therapy) and other language-based interventions (Warner, Spinazzola, Westcott, Gunn, \& Hodgdon, 2014). According to Warner et al. (2013), for interventions that are language-based, "the child must be sufficiently regulated, organized, grounded and present, such that language, imagination, and symbolic expressive function can emerge" (p. 730). These interventions are generally effective in treating children, but may be less effective for those who experience intense physiological symptoms (Perry, 2009; Raio, Orederu, Plazzolo, Shurick, \& Phelps, 2013; Wolf, 2013).

Somatic-based interventions, movement, and physical activities can help children develop self-regulation skills that help prepare them for traditional therapy interventions (Corrigan, Fisher, \& Nutt, 2010; Perry, 2009; van der Kolk, 2006; Warner et al., 2014). Latino children with histories of trauma may benefit from somatic-based interventions either in lieu of or as a precursor to language-based interventions. These interventions aim to decrease states of arousal and may be especially helpful for community-based mental health programs with limited resources or that lack bi-lingual services.

The purpose of this pilot study was to evaluate the impact of multi-phase therapy that combined a somatic-based intervention with a trauma-informed language-based cognitivebehavioral intervention for Latino youth to address symptoms and behaviors related to emotional dysregulation and physiological hyperarousal. We hypothesized that the use of a multi-phase intervention would be associated with a significant reduction in traumarelated symptoms including depression and anxiety. We also hypothesized that these reductions would be maintained at 3-month follow-up.

\section{Methods}

\section{Participants and setting}

This study used a one-group pretest-posttest follow-up design. All participants were Latino children and youth exposed to traumatic events and who experienced clinically significant psychological or behavioral symptoms. This convenience sample included selfreferrals and referrals from local schools or agencies to a community-based health clinic serving Latinos in a Midwestern city. The decision to not use control or comparison groups was based on the agency's reluctance to deny or delay services to their constituency.

A total of 53 participants enrolled in treatment. Out of that number, 24 (45\%) fully completed both the treatment and follow-up phases of the study. Eligibility criteria included: (1) ages between 5 and 20 years of age; (2) lifetime experience of a traumatic event as determined by the DSM-IV-TR which involves actual or threatened loss of life or serious injury to oneself or others causing intense fear or horror (APA, 2000); and (3) the experience of clinically significant psychological or behavioral symptoms. The study 
included a wide range of ages to maximize the number of persons who could be assisted by the intervention. The intervention was adapted to accommodate age differences on a case-by-case basis. Persons experiencing intellectual disabilities, active psychosis, suicidality, or who were receiving trauma-focused treatments or psychotropic medications in another setting were excluded. Eligible participants were guided through an informed consent process by a bi-lingual researcher. Informed consent documents were translated into Spanish by a professional service, using back-translation procedures. Ethical approval was obtained for this study from the Institutional Review Board at the host University of the principal investigators.

\section{Interventions}

The first author, a licensed clinical social worker employed at the agency at the time of the study, provided all treatment. This person developed the Somatic Soothing Intervention (SSI) Manual (Farina \& Silversmith, 2013) and was trained in Structured Sensory Intervention for Traumatized Children, Adolescents and Parents (SITCAP; Steele \& Malchiodi, 2012). To ensure fidelity, session checklists tracked the use of key intervention principles and activities. Participants received SSI until they were deemed physiologically stable enough to begin the SITCAP intervention. Some brief SSI activities were also used at the opening and ending of each SITCAP session.

Somatic Soothing: A Somatic-Based Intervention for the Treatment of Trauma. SSI helps children who experience hyper-arousal and dissociation develop skills that help them reach a state of stabilization. Key components of SSI include safety, choice, pace, success, checking in/mindfulness, and relaxation/breathing. The principles of SSI involve giving the child a sense of safety, mastery, and control. The intervention emphasizes the importance of checking in with the child about their internal experience throughout the intervention to help them build a sense and mindfulness of their internal experiences. Activities flow between activation and relaxation mimicking the body's natural rhythm of calming down after being activated.

Main categories of activities include relaxing, creating space and boundaries, movement, body resources, defending space, building core, and grounding. Relaxing activities counter the activation from the arousal activities such as rolling on a large exercise ball. There are a series of movement activities in which the child exerts some force with their bodies. Movement activities may be chosen based on problematic behaviors noted in a behavior checklist and can include activities such as squeezing the large exercise ball, rolling the ball up the wall, and running one's legs while pushing against a large stationary ball. Body resources are movements that invoke a sensation of calm used during times of stress (i.e., moving in hips, opening of the chest, stretching, hugging self, hugging legs to chest, putting hand to heart). Grounding resources help children learn how to stay present during dissociation such as lightly tapping on extremities. Clinicians continually assess the child to ensure activities are developmentally appropriate and engaging. They establish safety through routine and predictability, while also introducing new activities at the pace set by the child. 
This was the first study to test the effectiveness of SSI as a part of a multi-phase intervention. This intervention is based on research and theory on the use of somatic-based interventions to aid in decreasing hyperarousal symptoms as a means to prepare children for more cognitive-based interventions (Perry, 2009; van der Kolk, 2006; Warner et al., 2014). Interventions that contributed to the development of SSI include sensory diet activities (Wilbarger, 1984), Sensory Motor Arousal Regulation Treatment (Warner, Koomar, \& Westcott, 2009), Sensorimotor Psychotherapy (Ogden, Pain, \& Fisher, 2006), Impact Basics (Rosenblum \& Taska, 2014), and yoga.

Structured Sensory Intervention for Traumatized Children, Adolescents and Parents (SITCAP). SITCAP is a sensory and cognitive-based trauma intervention that was developed by the National Institute for Trauma and Loss for Children. SITCAP is considered a promising practice in SAMHSA's National Registry of Evidence-Based Programs and Practices and has been used in multiple settings with diverse children and adolescents. The intervention uses exposure, trauma narrative processing, and cognitive reframing through a series of drawing activities designed to process trauma while identifying thoughts, feelings, and body sensations (Steele \& Malchiodi, 2012).

\section{Assessment Measures}

Participants and/or their guardians completed a full assessment at three time periods: (1) prior to treatment (baseline); (2) upon completion of both phases of treatment (posttest); and (3) at three months after treatment (follow-up). The first author, who previously worked for more than ten years providing mental health services to Spanish-speaking individuals and families, performed all research interviews. All assessment tools not previously available in Spanish were translated by a professional translation service, using back-translation procedures. In addition, assessment tools were pilot-tested to ensure clarity and understanding. All parents and caregivers in this study chose to complete the assessment in Spanish.

Trauma symptomology. Trauma histories and symptoms were assessed using the UCLA PTSD Index for DSM-IV (Birman \& Chan, 2008; Pynoos, Rodriguez, Steinberg, Stuber, \& Frederick, 1998). This measure screens for the presence of any type of traumatic event and the frequency of DSM-IV PTSD symptoms in children, adolescents, and parents. A number of studies across cultures indicate that the UCLA PTSD Index has good validity and reliability of the scale in terms of both internal consistency and test-retest reliability (Birman \& Chan, 2008). For a sample of children and youth who have experienced at least one trauma, Steinberg et al. (2013) reported Cronbach's alpha across race/ethnicity from .88 to .90 . The measure has an overall severity score that can indicate the presence of a potential Post-Traumatic Stress Disorder condition and a clinical cut off score of 38 (Rodriguez, Steinberg, Saltzman \& Pynoos, 2001; Steinberg, Brymer, Decker, \& Pynoos, 2004).

Anxiety. Anxiety symptoms were assessed using the Screen for Child Anxiety Related Disorders (SCARED). The SCARED is a 41-item parent and child self-report screening instrument used to detect anxiety in children across the anxiety domains of panic/somatic, generalized anxiety, separation anxiety, social phobia, and school phobia (Birmaher et al., 
1999). Participants rated a series of questions as 0 (not true), 1 (somewhat true), and 2 (very true) over the previous 3 months. The clinical cutoff score for the measure is 25 . The SCARED has shown good convergent and divergent validity when compared to empirically supported scales such as the Child Behavior Checklist (CBCL) and the StateTrait Anxiety Inventory for Children (STAIC, Monga et al., 2000). Though a Castilian Spanish version has shown promise in Barcelona, Spain (Cronbach's alpha coefficient .83 and scale reliability between .44 and .72; Dobal, Martínez, \& Doménech-Llaberia, 2011), a Spanish version translated by a professional service was used due to language and cultural differences for this Latino sample.

Depression. Depression symptomatology was measured using the National Institute of Mental Health Center for Epidemiological Studies Depression Scale for Children (CESDC). The CES-DC is a 20-item self-report depression inventory with scores ranging from 0 to 60 , with a clinical cutoff score of 15 . Participants rate the frequency of a range of depressive symptoms as rarely ( $<1$ day), a little of the time (1-2 days), a moderate amount of time (3-4 days), and most/all of the time (5-7 days) over the past week. This scale is well established with good reliability and validity (Faulstich, Carey, Ruggiero, Enyart, \& Greshem, 1986; Weissman, Orvaschel, \& Padian, 1980). The CES-D has shown good reliability (alphas between .84 to .87 across four racial/ethnic groups [Anglo, Mexican, Cuban, and Puerto Rican]) and has been found appropriate for use with Mexican American youths (Crockett, Randall, Shen, Russell, \& Driscoll, 2005).

Psychosocial Functioning. Cognitive, emotional and behavioral functioning was assessed using the Pediatric Symptom Checklist (PSC). The PSC is a 35-item, parentcompleted screening questionnaire of children's psychosocial functioning (Jellinek et al., 1988). Parents rated the frequency of the items on a 3-point Likert scale ranging from 0 (never) to 2 (often). The clinical cutoff score on the PSC is 24 for younger children and 28 for older children. In validity studies the PSC has correlated highly with the Children's Global Assessment Scale (Shaffer et al., 1983) and the CBCL (Jellinek et al., 1988). The PSC showed good sensitivity, specificity, and internal consistency (Cronbach alpha score of .94) across gender and race/ethnicity among a group of children and youth (6-22 years old) enrolled in Medicaid (Boothroyd \& Armstrong, 2010).

Physiological Hyperarousal Checklist. The Physiological Hyperarousal Checklist is a 15-item parent self-report checklist developed by the first author. No reliability data currently exists. This measure was used in this study as opposed to the CBCL in this clinical setting and population due to the length and availability in Spanish and because of its clinical specificity in determining the somatic-based activities targeted towards decreasing hyperarousal behaviors. The measure asks about the frequency ranging from 0 (not at all) to 3 (a lot) of several hyperarousal behaviors including hitting, agitation, fighting, tantrums, etc. This instrument was developed in both English and Spanish.

Emotion Regulation Checklist (ERC). The ERC is a 23-item parent/caregiver report scale that assesses emotional regulation and dysregulation (Shields \& Cicchetti, 1997). The Emotion Regulation subscale (Cronbach's alpha $=.68$ ) consists of 8 items that assess emotional competence and the ability to empathize (Shields \& Cicchetti, 1997). The Negativity subscale includes 15 items that assess emotional dysregulation and reactivity. 
Higher scores on the Negativity subscale indicate decreased emotional regulation. Higher scores on the Emotional Regulation subscale indicate greater emotional regulation skills (Shields \& Cicchetti, 1997).

\section{Data Analysis}

Descriptive statistics were used to identify participant demographics and the mean scores for each measure at baseline, posttest, and follow-up observation points. Independent samples t-tests and paired t-tests were used to test for differences in scores based on gender and age level at baseline, post-test and 3-month follow-up for each of the measures and the number of trauma events experienced. For gender, females $(n=14)$ were coded as 0 and males $(n=10)$ were coded as 1 . For age, participants were split into two age groups. Participants aged 5 to $10(n=13)$ were coded as 0 and those aged 11 to $20(n=11)$ were coded as 1 . Due to the small sample size, it was not feasible to break participants into more age groups.

Paired sample t-tests were used to test the differences in baseline and post-intervention scores for each measure for the entire group. The same procedure was followed to compare posttest scores and scores collected at 3-month follow-up to see if gains were maintained. The alpha level was set to .01 to better control for Type I errors.

In the final dataset, scores for the depression (CES-D) and anxiety (SCARED) scales were missing for three participants. These missing scores were determined to be random and not due to systematic bias. Adding in mean scores for the missing data did not significantly alter scores or significance levels when compared to analyses that excluded these participants.

\section{Results}

\section{Participant Characteristics}

Table 1 displays the sociodemographic characteristics of the sample. The mean age for participants was 11.4 years and just over half the sample were aged 10 or older. The majority of the sample was female and born in the U.S. A third of the sample was born in Mexico. All of the parents/caregivers of the participants were born outside of the U.S. The average length of time between baseline and posttest was 12 weeks. Participants experienced on average 2.4 traumatic events $(S D=1.94)$. Females average 2.5 events, while males averaged 2.3 events. The most common events experienced were domestic violence and sexual assault. Over $83 \%$ of participants reported either experiencing or witnessing domestic violence, and almost $40 \%$ of the sample reported experiencing sexual abuse.

Independent samples t-tests were conducted to explore the presence of any sub-group differences. Males had significantly higher hyperarousal levels than females, $t(22)=-3.49$, $p=.002$. Younger participants had significantly higher posttest scores for emotional dysregulation, $t(22)=2.87, p=.009$. No other significant differences were found for age or gender across the three time periods. To test if any of these sub-group differences impacted treatment outcomes, four separate paired sample t-tests were conducted with each 
sub-group (males, females, younger and older). Similar to the full participant group, results showed significant differences in mean scores for each sub-group between baseline and posttest for trauma, anxiety, depression, psychosocial functioning, emotional dysregulation and physiological hyperarousal.

Table 1. Sociodemographic Characteristics of Sample $(n=24)$

\begin{tabular}{lc}
\hline Sociodemographic Factors & $\mathbf{n}(\mathbf{\%})$ \\
\hline Age Range & \\
5-9 years & $11(45.8 \%)$ \\
$10-15$ years & $6(25 \%)$ \\
$16-20$ years & $7(29.2 \%)$ \\
Gender & \\
Female & $14(58.3 \%)$ \\
Male & $10(41.7 \%)$ \\
Country of Origin & \\
United States & $14(58.3 \%)$ \\
Mexico & $8(33.3 \%)$ \\
Honduras & $2(8.3 \%)$ \\
Traumatic Events & \\
Witnessing Domestic Violence & $15(62.5 \%)$ \\
Experiencing Domestic Violence Directly & $5(20.8 \%)$ \\
Sexual Abuse & $9(37.5 \%)$ \\
Natural Disaster & $5(20.8 \%)$ \\
Bad Accident & $5(20.8 \%)$ \\
Experiencing or Witnessing Physical Assault & $3(12.5 \%)$ \\
\hline
\end{tabular}

\section{Trauma, Anxiety, Depression, Psychosocial Functioning, Emotional Regulation and Hyperarousal}

As shown in Table 2, participants reported clinically significant symptoms for trauma, depression, anxiety, and psychosocial functioning at baseline. Results showed that the severity levels of participants' symptoms of trauma, depression, and anxiety significantly decreased following participation in treatment. Posttest scores for trauma and depression dropped an average of $48 \%$, while anxiety posttest scores dropped an average of $42 \%$. Similar decreases in posttest scores were seen in psychosocial functioning, with an average decrease of $38 \%$ from baseline. Average posttest scores on the Negativity subscale of the ERC showed a $27 \%$ reduction in scores from baseline indicating decreased emotional dysregulation. Finally, there was a $45 \%$ reduction in posttest scores for physiological hyperarousal from baseline. Reductions in scores at three-month follow-up for trauma, depression, anxiety, psychosocial functioning, emotional dysregulation, and physiological hyperarousal were maintained. Scores on trauma significantly decreased further during follow-up, $t(23)=3.11, p=.005$. 
Table 2. Paired t-test Results for Baseline, Posttest, and 3-month Follow-up (n=24)

\begin{tabular}{|c|c|c|c|c|c|c|c|c|c|c|}
\hline \multirow[b]{2}{*}{ Outcome } & \multirow{2}{*}{$\begin{array}{l}\text { Baseline } \\
\text { M (SD) } \\
\end{array}$} & \multirow{2}{*}{$\begin{array}{l}\text { Posttest } \\
\text { M (SD) }\end{array}$} & \multirow[b]{2}{*}{$\begin{array}{c}\text { Mean } \\
\text { Diff. }\end{array}$} & \multirow[b]{2}{*}{$95 \% \mathrm{CI}$} & \multirow[b]{2}{*}{$\mathbf{t}(\mathbf{2 3})$} & \multirow{2}{*}{$\begin{array}{c}\text { Posttest } \\
\text { M (SD) }\end{array}$} & \multirow{2}{*}{$\begin{array}{c}\text { Follow-up } \\
\text { M (SD) }\end{array}$} & \multirow[b]{2}{*}{$\begin{array}{l}\text { Mean } \\
\text { Diff. }\end{array}$} & \multirow[b]{2}{*}{$95 \%$ CI } & \multirow[b]{2}{*}{$\mathbf{t}(23)$} \\
\hline & & & & & & & & & & \\
\hline Trauma & $43.8(11.3)$ & $22.8(8.7)$ & 21.0 & $17.10,24.73$ & $* 11.34$ & $22.8(8.7)$ & $19.3(8.4)$ & 3.5 & $1.17,5.83$ & $* 3.11$ \\
\hline Depression & $20.6(9.9)$ & $10.8(5.5)$ & 9.8 & $6.72,12.90$ & $* * 6.57$ & $10.8(5.5)$ & $10.2(5.3)$ & 0.6 & $-1.07,2.12$ & .678 \\
\hline Anxiety & $33.3(11.7)$ & $19.4(7.0)$ & 13.9 & $9.82,17.99$ & *7.05 & $19.4(7.0)$ & $17.8(6.0)$ & 1.6 & $-.336,3.57$ & 1.71 \\
\hline $\begin{array}{l}\text { Psychosocial } \\
\text { Functioning }\end{array}$ & $24.8(11.0)$ & $15.3(7.5)$ & 9.5 & $6.34,12.74$ & $* * 6.17$ & $15.3(7.5)$ & $14.5(7.0)$ & 0.8 & $-1.33,2.74$ & .720 \\
\hline $\begin{array}{l}\text { Emotional } \\
\text { Dysregulation }\end{array}$ & $31.9(10.9)$ & $23.2(10.0)$ & 8.7 & $4.21,13.21$ & $* 4.01$ & $23.2(10.0)$ & $23.0(9.4)$ & 0.2 & $-2.44,2.78$ & .132 \\
\hline $\begin{array}{l}\text { Emotional } \\
\text { Regulation }\end{array}$ & $24.5(4.8)$ & $27.5(5.1)$ & -3.0 & $-5.32,-0.68$ & -2.679 & $27.5(5.1)$ & $26.5(5.8)$ & 1.0 & $-1.59,3.59$ & .800 \\
\hline $\begin{array}{l}\text { Physiological } \\
\text { Hyperarousal }\end{array}$ & $17.3(8.6)$ & $9.5(7.9)$ & 7.8 & $5.49,9.93$ & $* * 7.19$ & $9.5(7.9)$ & $8.7(6.5)$ & 0.8 & $-.882,2.55$ & 1.01 \\
\hline
\end{tabular}




\section{Discussion}

This pilot study explored the usefulness of a multi-phased, trauma-focused intervention with 24 Latino youth experiencing significant trauma-related symptomatology. Participants reported significant reductions in symptomology after intervention, which were maintained at 3-month follow-up. Developing emotional stability and physiological calming may provide benefits for those not ready to undertake the intense work of trauma reprocessing due to mistrust, cultural barriers, lack of access to adequate bi-lingual services, or lack of emotional readiness to address traumatic experiences directly.

While this intervention could provide benefits across multiple cultural groups, it may be particularly beneficial to Latino populations in at least three ways. First, Latino parents are less likely to seek mental health services for their children (Gudiño, Lau, \& Hough, 2008). This intervention has the potential to decrease problematic behaviors in a targeted and safe manner without addressing trauma events before families are ready to discuss them safely.

Second, Latinos may also be more likely to meet criteria for PTSD following a traumatic event, report greater severity in symptoms, and experience their symptoms for longer periods of time (Alcántera et al., 2013; Galea et al., 2004; Lewis-Fernandez et al., 2008). Studies have also found differences in the consequences of sexual abuse among Latinas, including greater psychological, emotional, and behavioral difficulties than African-American and White females (Lefley, Scott, Liabre, \& Hicks, 1993; Shaw, Lewis, Loeb, Rosado, \& Rodriguez, 2001). In addition, Marshall et al. (2009) found evidence suggesting that Latinos may be more likely to experience hyperarousal symptoms such as hypervigilience and emotional reactivity than non-Hispanic Caucasians. These factors may suggest that Latinos, in particular, may benefit from interventions designed to reduce somatic symptomatology related to trauma. Third, Latino youth are at risk of experiencing traumatic events (Cuevas et al., 2012; Dettlaff \& Johnson, 2011; Fortuna et al., 2008; Kaltman, Green, Mete, Shara, \& Miranda, 2010; Sedlack et al., 2010) also placing them at risk for complex trauma. Indeed, our sample experienced multiple trauma events that included high rates of violence and high degrees of trauma symptomatology including physiological arousal and emotional dysregulation. Latino youth exposed to multiple traumas may benefit from somatic-based interventions, particularly prior to undergoing language-based interventions such as TF-CBT, which work best when youth are physiologically and emotionally regulated and can express feelings and thoughts effectively to a practitioner (Perry, 2009; Raio et al., 2013; Warner et al., 2013; Warner et al., 2014; Wolf, 2013). These somatic-based interventions may be beneficial in agencies with limited clinical capacity or bi-lingual resources that serve Latino populations.

Several limitations exist in the present study. First, the study employed a one-group pretest-posttest design with a small convenience sample. A waitlist-control was not implemented due to the request of the organization and in attempts to encourage individuals seeking treatment, especially in this community with low mental health service utilization. This design limited the ability to control for various threats to internal validity. Future research should assess the impact of this intervention using a randomized control design 
with a larger, more diverse sample. Second, the dropout rate in the study was high (45\%). Reasons for incomplete participation include lack of transportation, mistrust, change of residence or work schedules, symptom improvement, or a lack of treatment readiness, among others. Third, due to design limitations it cannot be determined if one phase of treatment (i.e., Somatic Soothing vs. SITCAP) had a disproportionate effect on symptoms compared to the other phase. Future research should rely on randomized control groups that assess the impact of each phase of the intervention. Lastly, there are limitations in the measurement instruments that we used because of the lack of psychometric testing with Latino children and youth, which may impact the reliability of test scores and interpretation.

\section{References}

Alcántera, C., Casement, M. D., \& Lewis-Fernández, R. (2013). Conditional risk for PTSD among Latinos: A systematic review of racial/ethnic differences and sociocultural explanations. Clinical Psychology Review, 33, 107-119. doi: https://doi.org/10.1016/j.cpr.2012.10.005

American Psychiatric Association. (2000). Diagnostic and statistical manual of mental disorders ( $4^{\text {th }}$ ed., text rev.). Washington, DC: Author.

Birmaher, B., Brent, D. A., Chiappetta, L., Bridge, J., Monga, S., \& Baugher, M. (1999). Psychometric properties of the Screen for Child Anxiety Related Emotional Disorders (SCARED): A replication study. Journal of the American Academy of Child and Adolescent Psychiatry, 38(10), 1230-1236. doi: https://doi.org/10.1097/00004583-199910000-00011

Birman, D., \& Chan, W. Y. (2008, May). Screening and assessing immigrant and refugee youth in school-based mental health programs. Washington DC: Center for Health and Health Care in Schools.

Boothroyd, R. A., \& Armstrong, M. (2010). An examination of the psychometric properties of the Pediatric Symptom Checklist with children enrolled in Medicaid. Journal of Emotional and Behavioral Disorders, 18(2), 113-126. doi: https://doi.org/10.1177/1063426609337604

Buckner, J. C., Mezzacappa, E., \& Beardslee, W. R. (2009). Self-regulation and its relations to adaptive functioning in low income youths. American Journal of Orthopsychiatry, 79(1), 19-30. doi: https://doi.org/10.1037/a0014796

Cook, A., Spinazzola, J., Ford, J., Lanktree, C., Blaustein, M. Cloitre,...van der Kolk, B. (2005). Complex trauma in children and adolescents. Psychiatric Annals, 35, 390398.

Corrigan, F. M., Fisher, J. J., \& Nutt, D. J. (2010). Autonomic dysregulation and the window of tolerance model of the effects of complex emotional trauma. Journal of Psychopharmacology, 25(1), 17-25. doi: https://doi.org/10.1177/0269881109354930

Crockett, L. J., Randall, B. A., Shen, Y., Russell, S. T., \& Driscoll, A. K. (2005). Measurement equivalence of the Center for Epidemiological Studies Depression 
Scale for Latino and Anglo adolescents: A national study. Journal of Consulting and Clinical Psychology, 73(1), 47-58. doi: https://doi.org/10.1037/0022-006X.73.1.47

Cuevas, C. A., Sabina, C., \& Milloshi, R. (2012). Interpersonal victimization among a national sample of Latino women. Violence Against Women, 18(4), 377-403. doi: https://doi.org/10.1177/1077801212452413

Dettlaff, A. J., \& Johnson, M. A. (2011). Child maltreatment dynamics among immigrant and U.S. born Latino children: Findings from the National Survey of Child and Adolescent Well-being (NSCAW). Children and Youth Services Review, 33, 936944. doi: https://doi.org/10.1016/j.childyouth.2010.12.017

Dobal, E., Martínez, M., \& Doménech-Llaberia, E. (2011). Evidencias de salidad psicométrica de la version en Castellano del Screen for Child Anxiety Related Emotional Disorders (SCARED) de 41 items. Ansiedad y Estrés, 17(2-3), 199-210.

Farina, A.S.J., \& Silversmith, K. (2013). Somatic Soothing manual for clinicians. Unpublished manuscript.

Faulstich M. E., Carey M. P., Ruggiero L., Enyart, P., \& Gresham, F. (1986). Assessment of depression in childhood and adolescence: An evaluation of the Center for Epidemiological Studies Depression Scale for Children (CES-DC). American Journal of Psychiatry 143(8), 1024-1027. doi: https://doi.org/10.1176/ajp.143.8.1024

Fortuna, L., Porche, M., \& Alegria, M. (2008). Political violence, psychosocial trauma, and the context of mental health services among immigrant Latinos in the United States. Ethnicity \& Health, 13, 435-463. doi: https://doi.org/10.1080/13557850701837286

Galea, S., Vlahov, D., Tracy, T., Hoover, D. R., Resnick, H., \& Kilpatrick, D. (2004). Hispanic ethnicity and post-traumatic stress disorder after a disaster: Evidence from a general population survey after September 11, 2001. Annals of Epidemiology, 14, 520-531. doi: https://doi.org/10.1016/j.annepidem.2004.01.006

Gudiño, O. G., Lau, A. S., \& Hough, R. L. (2008). Immigrant status, mental health need, and mental health service utilization among high-risk Hispanic and Asian Pacific Islander youth. Child \& Youth Care Forum, 37, 139-153. doi: https://doi.org/10.1007/s10566-008-9056-4

Jellinek, M. S., Murphy, J. M., Robinson, J., Feins, A., Lamb, S., \& Fenton, T. (1988). The Pediatric Symptom Checklist: Screening school-age children for psychosocial dysfunction. Journal of Pediatrics, 112, 201-209. doi: https://doi.org/10.1016/S00223476(88)80056-8

Kaltman, S., Green, B. L., Mete, M., Shara, N., \& Miranda, J. (2010). Trauma, depression, and comorbid PTSD/depression in a community sample of Latina immigrants. Psychological Trauma: Theory, Research, Practice, and Policy, 2, 2931. doi: https://doi.org/10.1037/a0018952 
Lawson, D. M., \& Quinn, J. (2013). Complex trauma in children and adolescents: Evidence-based practice in clinical settings. Journal of Clinical Psychology: In Session, 69(5), 497-509. doi: https://doi.org/10.1002/jclp.21990

Lefley, H. P., Scott, C. S., Liabre, M., \& Hicks, D. (1993). Cultural beliefs about rape and victims response in three ethnic groups. American Journal of Orthopsychiatry, 64(4), 623-632. doi: https://doi.org/10.1037/h0079477

Lewis-Fernandez, R., Turner, J. B., Marshall, R., Turse, N., Neria, Y., \& Dohrenwend, B. P. (2008). Elevated rates of current PTSD among Hispanic veterans in the NVVRS: True prevalence or methodological artifact? Journal of Traumatic Stress, 21, 123132. doi: https://doi.org/10.1002/jts.20329

Marshall, G. N., Schell, T. L., \& Miles, J. N. V. (2009). Ethnic differences in posttraumatic distress: Hispanics' symptoms differ in kind and degree. Journal of Consulting and Clinical Psychology, 77(6), 1169-1178. doi: https://doi.org/10.1037/a0017721

Monga, S., Birmaher, B., Chiappetta, L., Brent, D., Kaufman, J., Bridge, J., \& Cully, M. (2000). Screen for Child Anxiety-Related Emotional Disorders (SCARED): Convergent and divergent validity. Depression and Anxiety, 12(2), 85-91. doi: https://doi.org/10.1002/1520-6394(2000)12:2<85::AID-DA4>3.0.CO;2-2

Ogden, P, \& Minton, K. (2000). Sensorimotor psychotherapy: One method for processing traumatic memory. Traumatology, 3(3), 149-173. doi: https://doi.org/10.1177/153476560000600302

Ogden, P., Pain, C., \& Fisher, J. (2006). A sensorimotor approach to the treatment of trauma and dissociation. Psychiatry Clinics of North America, 29, 263-279. doi: https://doi.org/10.1016/j.psc.2005.10.012

Perry, B. D. (2009). Examining child maltreatment through a neurodevelopmental lens: Clinical application of the Neurosequential Model of Therapeutics. Journal of Loss and Trauma, 14, 240-255. doi: https://doi.org/10.1080/15325020903004350

Pynoos, R. S., Rodriguez, N., Steinberg, A., Stuber, M., \& Frederick, C. (1998). The UCLA posttraumatic stress reaction index for DSM-IV. Los Angeles: UCLA Trauma Psychiatry Program.

Raio, C. M., Orederu, T. A., Plazzolo, L., Shurick, A. A., \& Phelps, E. A. (2013). Cognitive emotional regulation fails the stress test. Proceedings of the National Academy of Sciences, 110(37), 15139-15144. doi: https://doi.org/10.1073/pnas.1305706110

Rodriguez, N., Steinberg, A. S., Saltzman, W. S., \& Pynoos, R. S. (2001). PTSD Index: psychometric analysis of the adolescent version. Symposium conducted at the Annual Meeting of the International Society for Traumatic Stress Studies, New Orleans: LA.

Rojas-Flores, L., Clements, M. L., Koo, J. H., \& London, J. (2016). Trauma and psychological in Latino citizen children following parental detention and deportation. 
Psychological Trauma: Theory, Research, Practice, and Policy, 9(3), 352-361. doi: https://doi.org/10.1037/tra0000177

Rosenblum, G. D., \& Taska, L. S. (2014). Self-defense training as clinical intervention for survivors of trauma. Violence Against Women, 20(3), 293-308. doi: https://doi.org/10.1177/1077801214526048

Sedlak, A. J., Mettenburg, J., Basena, M., Petta, I., McPherson, K., Greene, A., \& Li, S. (2010). Fourth national incidence study of child abuse and neglect (NIS-4): Report to Congress. Washington, DC: U.S. Department of Health and Human Services, Administration for Children and Families. Retrieved from https://www.acf.hhs.gov/sites/default/files/opre/nis4_report_congress_full_pdf_jan20 10.pdf

Shaffer, D., Gould, M.S., Brasic, J., Ambrosini, P., Fisher, P., Bird, H., \& Aluwawhlia, S. (1983). A children's global assessment scale (CGAS). Archives of General Psychiatry, 40, 1228-1231.

Shaw, J. A., Lewis, J. E., Loeb, A., Rosado, J., \& Rodriguez, R. A. (2001). A comparison of Hispanic and African-American sexually abused girls and their families. Child Abuse \& Neglect, 25, 1363-1379. doi: https://doi.org/10.1016/S0145-2134(01)00272$\underline{1}$

Shields, A., \& Cicchetti, D. (1997). Emotion regulation among school-age children: The development and validation of a new criterion q-sort scale. Developmental Psychology, 33(6), 906-916. doi: https://doi.org/10.1037/0012-1649.33.6.906

Steele, W., \& Malchiodi, C. A. (2012). Trauma-informed practices with children and adolescents. New York: Routledge.

Steinberg, A. M., Brymer, M. J., Kim, S., Briggs, E. C., Ippen, C. G., Ostrowski, S. A., Gully, K. J., \& Pynoos, R. S. (2013). Psychometric properties of the UCLA PTSD Reaction Index: Part I. Journal of Traumatic Stress, 26, 1-9. doi: https://doi.org/10.1002/jts.21780

Steinberg, A.M., Brymer, M.J., Decker, K.B., \& Pynoos, R.S. (2004). The University of California at Los Angeles Post-traumatic Stress Disorder Reaction Index. Current Psychiatry Reports, 6, 96-100.

U.S. Department of Health and Human Services, Administration on Children, Youth, and Families. (2015). Child Maltreatment 2015. Washington, D.C.: U.S. Government Printing Office. Retrieved from https://www.acf.hhs.gov/sites/default/files/cb/cm2015.pdf

van der Kolk, B. A. (1994). The body keeps the score: Memory and the evolving psychobiology of posttraumatic stress. Harvard Review of Psychiatry, 1(5), 252-265. doi: https://doi.org/10.3109/10673229409017088

van der Kolk, B. A. (2006). Clinical implications of neuroscience research in PTSD. Annals of the New York Academy of Sciences, 1071, 277-293. doi: https://doi.org/10.1196/annals.1364.022 
Warner, E., Koomar, J., Lary, B., \& Cook, A. (2013). Can the body change the score? Application of sensory modulation principles in the treatment of traumatized adolescents in residential settings. Journal of Family Violence, 28(7), 729-738. doi: https://doi.org/10.1007/s10896-013-9535-8

Warner E., Koomar, J., \& Westcott, A. (2009). Arousal regulation in traumatized children: Sensorimotor interventions [PowerPoint slides]. Retrieved from http://www.traumacenter.org/announcements/TConf.09_SMART_Handouts.pdf

Warner, E., Spinazzola, J., Westcott, A., Gunn, C., \& Hodgdon, H. (2014). The body can change the score: Empirical support for somatic regulation in the treatment of traumatized adolescents. Journal of Child \& Adolescent Trauma, 7, 237-246. doi: https://doi.org/10.1007/s40653-014-0030-Z

Weissman, M. M., Orvaschel, H., \& Padian, N. (1980). Children's symptom and social functioning self-report scales. Comparison of mothers' and children's reports. The Journal of Nervous and Mental Disease, 168(12), 736-740. doi: https://doi.org/10.1097/00005053-198012000-00005

Wilbarger, P. (1984). Planning an adequate "sensory diet"--Application of sensory processing theory during the first year of life. Zero to Three, 5(1), 7-12.

Wolf, E. J. (2013). The Dissociative Subtype of PTSD: Rationale, evidence, and future directions. PTSD Research Quarterly, 24(4), 1-8.

Author note: Address correspondence to: Anne Farina, School of Social Work, Saint Louis University, Tegeler Hall, 3550 Lindell Boulevard, Saint Louis, MO 63103, farinaas@slu.edu 